\title{
An Experimental Investigation of a Darrieus Straight-Bladed Wind Turbine
}

\author{
K. A. Ibrahim ${ }^{1}$, W. A. El-Askary ${ }^{2}$, Tarek A. Ghonim ${ }^{3}$ and Ahmed M. Nebiewa ${ }^{4}$ \\ ${ }^{1}$ Prof., Faculty of Engineering, Menoufia University, Egypt. \\ ${ }^{2}$ Prof., Alexandria Higher Instituteof Engineering and Technology (AIET), Egypt. \\ ${ }^{3}$ Lecturer, Faculty of Engineering, Menoufia University, Egypt. \\ ${ }^{4}$ Demonstrator, Faculty of Engineering, Menoufia University, Egypt.
}

\begin{abstract}
Wind energy is the fastest growing energy in the world today. Vertical axis wind turbine (VAWT) is an effective way to benefit from this energy. So that, the present work aims to improve the performance of Darrieus straight bladed rotor. For improving the performance Darrieus straight bladed rotor, six aspect ratios and four chord lengths of Darrieus rotor are experimentally selected in an attempt to improve the performance of Darrieus wind turbine. The experimental results in the present work are obtained using three blades of a new airfoil shape design which is designated as EN0005 at different wind speeds. The comparison between six aspect ratios at the same wind speed and chord length showed that, the rotor with aspect ratio 0.833 and chord length $18 \mathrm{~cm}$ produces the maximum power coefficient.
\end{abstract}

$$
\begin{aligned}
& \text { ملخص البحث: } \\
& \text { طاقة الرياح من اسرع الطاقات نموا في العالم في الايام الحاليه. وتعتبر التربينات الهوائيه ذات المحور الرئسي من افضل الطرق }
\end{aligned}
$$

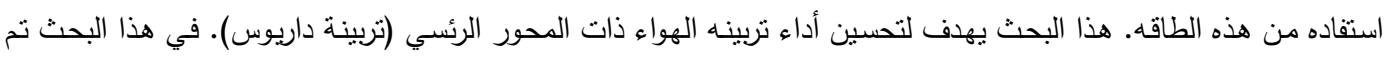

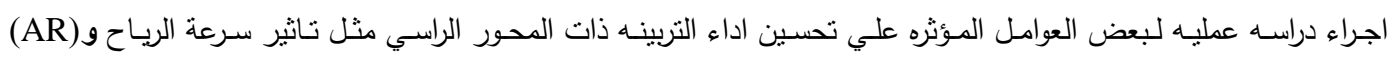

$$
\begin{aligned}
& \text { chord lengths (CL) وقد أجريت مقارنات بين سته aspect ratios و و اربعه chord lengths } \\
& \text { سرعات رباح مختلفه. وقد أوضحت الدراسة زيادة أداء التربينه عند }
\end{aligned}
$$

Keywords: Darrieus rotor; self-starting; aspect ratio; chord length; power coefficient

\section{1- INTRODUCTION}

Recently, the energy demands have increased and the conventional energy resources that used coal, oil and natural gas to produce the energy caused a negative impact on the environment like the greenhouse gases. So many conferences have been held to discuss this serious problem and the big industrial countries have reached an agreement to reduce the emissions by using a renewable and friendly energy for the environment. So that, the demand and improvement of the resources of renewable energy have increased in the last decade. One of

the most important resources of the renewable energy is the wind energy.Wind energy is the fastest growing energy in the world and the wind power capacity worldwide by the end of 2018 reached 600 Gig Watt and 53.9 GW added in 2018, according to preliminary statistics published by the world wind energy association (WWEA),[1].Moreover, to convert wind energy into mechanical energy, the most effective way is wind turbine. Where, the kinetic energy available in the wind is converted to torque by the blades of the wind turbine and this torque

rotates the shaft and hence, the mechanical energy is generated. Finally, the mechanical energy is converted into electrical energy by using the generator. The wind turbine is classified into two categories Horizontal Axis (HAWT) and Vertical Axis (VAWT). Nowadays, the world focuses on the HAWTs because they produce more energy and have more efficiency compered to VAWTs. But, HAWTs are difficult to use in urban areas because, the flow changes in velocity and direction so that, the VAWTs are suitable in these places. VAWTs have many advantages compered to Horizontal Axis Wind Turbines such as, simple construction, low installation and maintenance cost, low operating wind speed, and an ability to operate in any wind direction; Thus, they are useful for installation as a low cost, small scale decentralized energy 
generation device [2],[3] but, it has low aerodynamic efficiency, and a new design is proposed to improve the efficiency of VAWTs.The VAWTs can be divided into two types: Savonius wind turbine and Darrieus wind turbine. Savonius wind turbine depends on the drag force from the wind that rotates the blades and hence, rotates the Savonius rotor. Darrieus wind turbine depends on the lift force from the wind that rotates the blades and the Darrieus blades have an airfoil shape. Darrieus wind turbine has several disadvantage such as, inability to selfstart and to overcome this problem, several solutions have been proposed such that, the use of guide-vane [4], optimizing the blade pitch angle [5], using a savonius wind turbine and Darrieus wind turbine together (hybrid configuration) [6], using blade profile aid offers self-start capabilities without using external components [7][9]. Soni and Thakkar [8] presented a review on the aerodynamic performance evaluation of straight blade vertical axis wind turbine. They described some parameters which affect the performance of these turbines such as number of blades, turbine solidity, airfoil selection, blade pitch angle and turbine aspect ratio (H/D). it was found that 3 blades VAWT is more efficient than 2 or 4 blades. Solidity of $0.2-0.4$ are more efficient. also, It has been found that the pitch angle, turbine radius and chord length have a significant effect on the turbine power coefficient. Batista et al. [9-11] presented a new blade profile for Darrieus wind turbine capable to self-start at low wind speeds which the new airfoil is called EN0005. Also, they used other airfoils such as NACA 0018 and NACA 4418 to compare with the new blade shape. In addition to that, they studied the influence of the chamber size and the influence of the chamber position for different NACA blades profiles. Finally, their results showed that the new airfoil EN0005 is capable of self-starting without the use of external energy input like external electricity feed. This blade gives high performance at low wind speed and low TSR and gives also a good performance at high wind speed and high TSR. Also, they studied the influence of the chamber size and the chamber position and they found that when the airfoils with chamber positioned in the middle of the blade chord line and with curve sizes between $4 \%$ and $6 \%$ of the chord line size provide a better performance regarding self-start capabilities. Sengupta et al. [12] found also that the new blade EN0005 exhibits minimum starting time from static position. Also, they used three different rotor aspect ratios $[0.9,1.0$ and 1.1] for three different wind speeds $[4 \mathrm{~m} / \mathrm{s}, 6 \mathrm{~m} / \mathrm{s}$, $8 \mathrm{~m} / \mathrm{s}$ ] to study the performance of the turbine. Alexandru-Mihai et al. [13] proposed a new urban design to enhance the overall performance of the urban H-rotor vertical axis wind turbine by adding a second set of blades. They used NACA 0018 airfoil with 0.48 solidity and $\mathrm{TSR}=1$. Their results showed that, the new vertical axis wind turbine (biplane configuration) yields an increased lift that leads to increase of the power coefficient. Mojtaba et al. [14] proposed a novel heuristic method for optimization of straight blade vertical axis wind turbine. They used six types of airfoils with different parameters such as $(0.05 \leq$ chord $\geq 0.1 \mathrm{~m}),(1 \leq$ Diameter $\geq 2.5$ $\mathrm{m})$ and number of blades $=2,3$ and 4 . The maximum power coefficient of the optimized turbine calculated by (DMST) model is $44 \%$ higher than the original turbine power coefficient. The best solidity for achieving the maximum average power coefficient is equal to 0.254 . The value of chord and diameter was selected to be to $0.1 \mathrm{~m}$ and $1.18 \mathrm{~m}$ and the number of blades was chosen to be 3 with NACA4412 airfoil type was selected as the best configuration. ElSamanoudy et al. [15] studied the effect of pitch angle, number of blades, airfoil type, turbine radius and its chord length on the performance of VAWT. They used three different types of NACA airfoil (NACA 0024, NACA 4420 and NACA 4520) with different chord lengths and pitch angles. Their results showed that, the symmetrical airfoil NACA 0024 gives higher performance compared to the cambered airfoil. Also, the performance increased with increasing the chord length and decreased with decreasing the turbine radius.

The present work aims to improve the performance and self-starting capability of straight-bladed Darrieus rotor. For improving the performance and solving the problem of self-starting capability, six aspect ratios and four chord lengths of Darrieus rotor were experimentally selected in an attempt to improve the performance of Darrieus wind turbine. The experimental results in the present work are obtained using 3-blades turbine using the new profile named EN0005 at different wind speeds.

\section{2- Experimental Apparatus:}

In order to carry out experimental investigation of a straight-bladed Darrieus wind turbine, a testing apparatus is designed and constructed. The present experimental test rig is based on the previously explained and used by Nasef.et al. [16] with successful results. The test rig is illustrated schematically in Fig. 1. It consists of: a centrifugal fan with maximum air speed $14 \mathrm{~m} / \mathrm{s}$ at the exit. AC motor of $1480 \mathrm{rpm}$ and $15 \mathrm{HP}$ rated power is used to drive the fan. Duct is connected to the fan with a square cross section and $1.5 \mathrm{~m}$ length and $1.5 \mathrm{~mm}$ thickness. The model of the turbine has the following specifications: hollow steel shaft with $30 \mathrm{~mm}$ diameter, three blades (EN 0005) with four different chord length $(12,14,16,18 \mathrm{~cm})$ respectively and 40 $\mathrm{cm}$ height, steel link is used to connected the blades with the shaft, four ball bearing (SKF) are mounted to fix the turbine rotor with frame and a steel frame is used to fix the turbine. The blades are fabricated 
from fiber glass material by casting process. The turbine rotor is placed at the center position in the front of the duct exit as shown in Fig.1. The technical specifications of Darrieus turbine rotor are listed in Table (1)

Table (1): Darrieus rotor specifications

\begin{tabular}{|l|l|}
\hline Blade airfoil [-] & EN 0005 \\
\hline Number of blades (n) [-] & 3 \\
\hline Blade length (L) [m] & 0.4 \\
\hline chord length (CL) [m] & $\begin{array}{l}0.12,0.14, \quad 0.16 \\
\text { and 0.18 }\end{array}$ \\
\hline Rotor diameter (D) [m] & $0.308-0.5$ \\
\hline Rotational speed (N) [rpm] & $50-750$ \\
\hline Wind speed (U) [m/s] & $6-12$ \\
\hline
\end{tabular}

\section{3- Measurements and instrumentation:}

An air anemometer is used to measure air velocity. It had an operating range of $(0.4-25.0) \mathrm{m} / \mathrm{s}$, and an accuracy of $0.2 \mathrm{~m} / \mathrm{s}$ (Model: AM-4206 Anemometer) as shown in Fig. 2. A digital laser tachometer illustrated in Fig. 3 is used to measure the rotational speed of the rotating turbine shaft with an operating range of (1-10000) rpm, and an accuracy of $0.5 \mathrm{rpm}$ (Model: GTC-TA110 laser tachometer). Moreover, Fig. 4 shows photographically the digital torque meter used to measure the torque generated by the turbine rotor. It has an operating range of ( -5 to + 5) N.m, (Model: MCRT-48200v Compact digital torque meter).

\section{3- Results and discussion:}

Various measured parameters are used to study and analyze the performance of Darrieus wind turbine such as the average wind speed, aspect ratio (AR) and chord length. Where, the aspect ratio (AR) is defined as the ratio between the blade height $(\mathrm{H})$ and the rotor diameter (D), which is given by equation. (1) and the performance of the turbine is assessed by calculating the power coefficients, $\mathrm{Cp}$ and tip speed ratio, $\lambda$ are given in equations 2 and 3 respectively

$$
\begin{aligned}
& A R=\frac{H}{D} \\
& C_{P}=\frac{T \cdot \omega}{0.5 \rho A U^{3}} \\
& \lambda=\frac{\omega R}{U}
\end{aligned}
$$

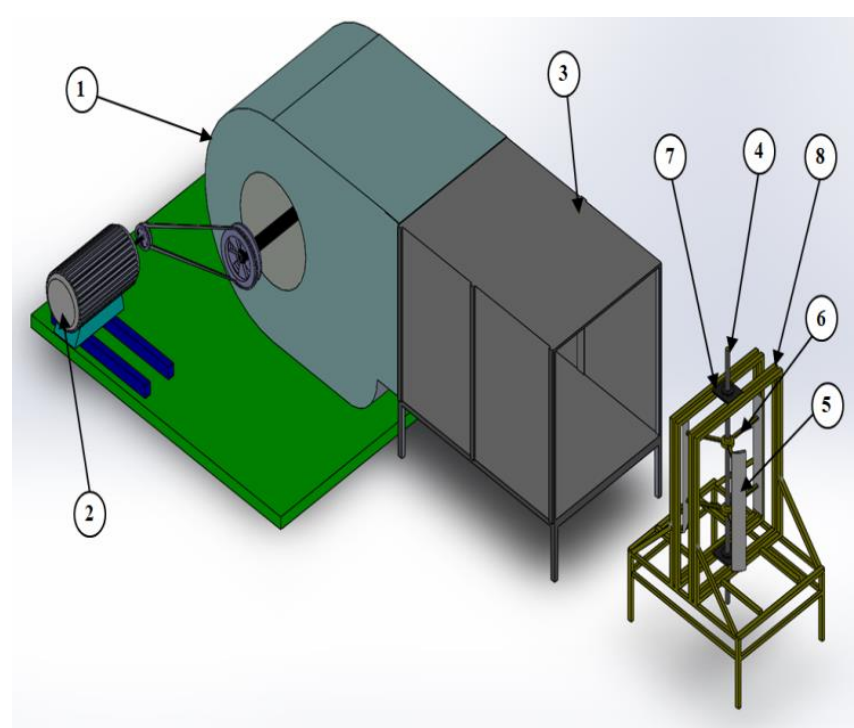

(a) an isometric view

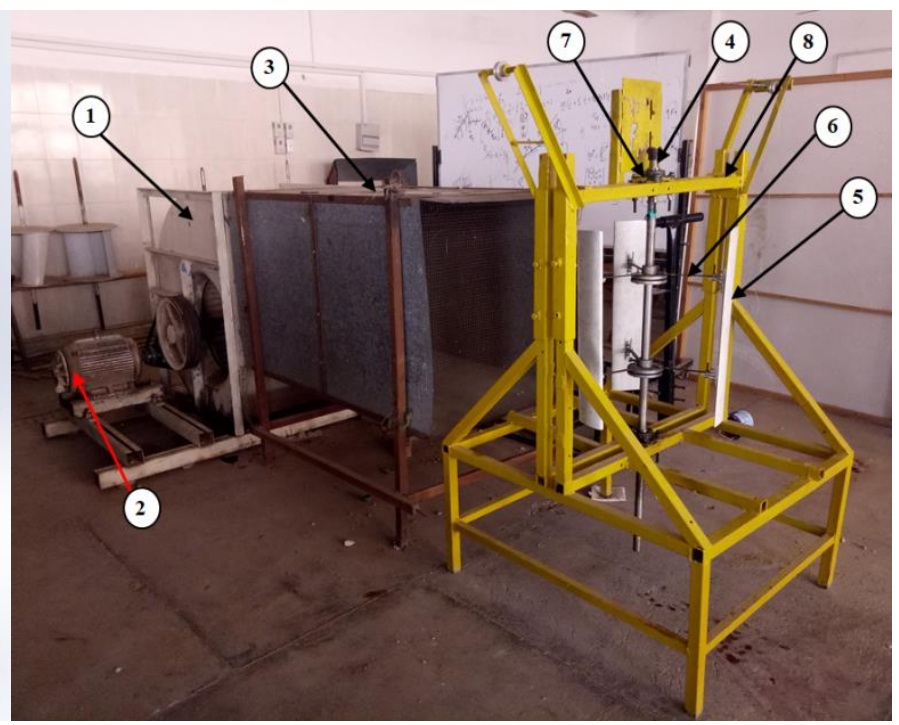

(b) a photo of the experimental set-up

(1) Centrifugal fan, (2) AC motor, (3) fan exit duct, (4) rotating shaft, (5) blades, (6) steel links, (7) bearings, (8) steel suspension frame

Fig. 1 An illustrative figure of the experimental test rig, (a) An isometric view, (b) a Photo 


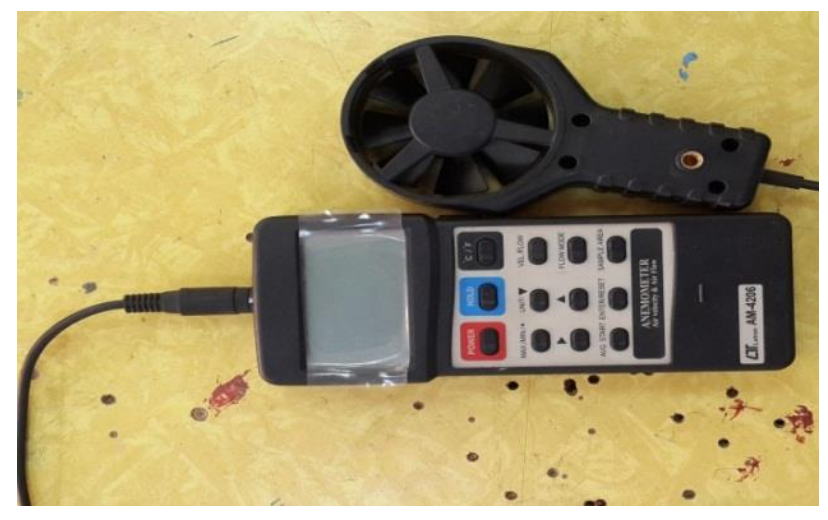

Fig.2 A photo of the air anemometer

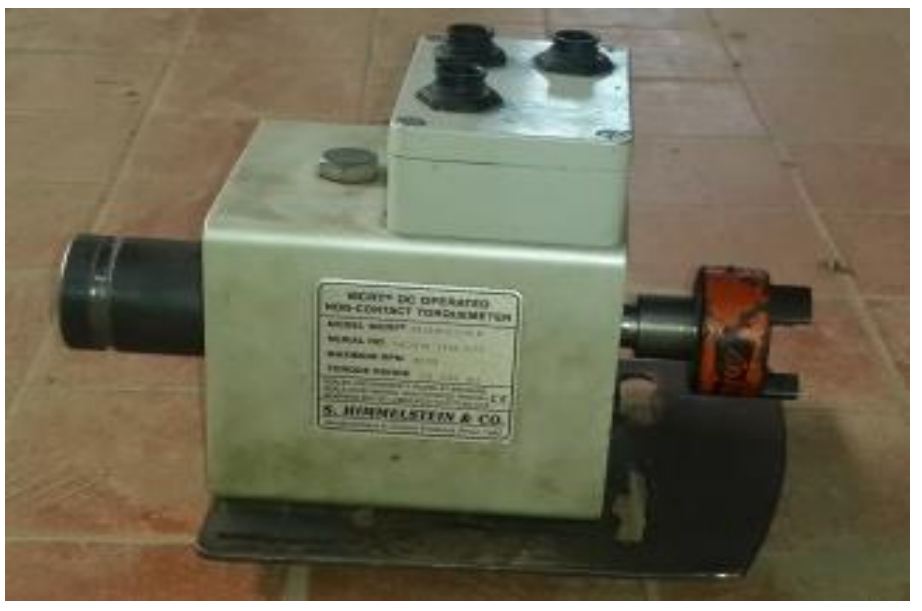

Fig. 4 A photo of the torque meter

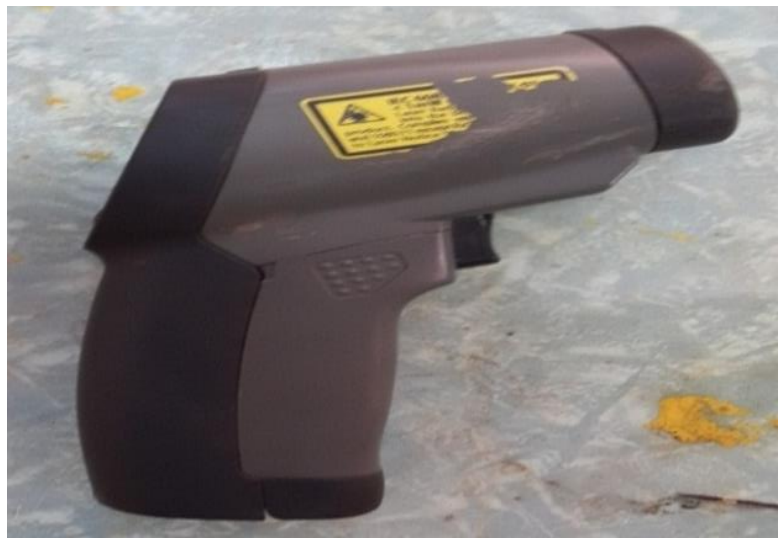

Fig. 3 A photo of the digital laser tachometer

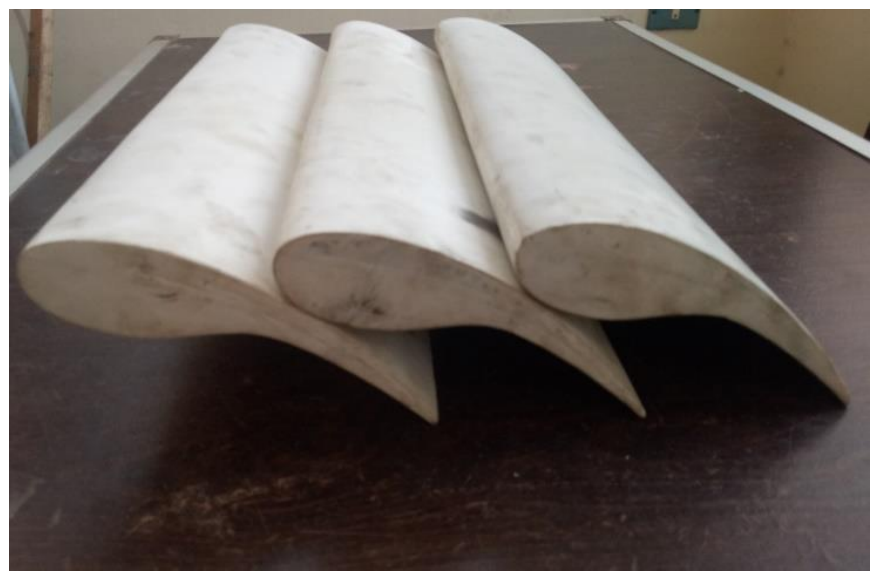

Fig.5 A photo of EN0005 blades with $0.18 \mathrm{~m}$ chord length

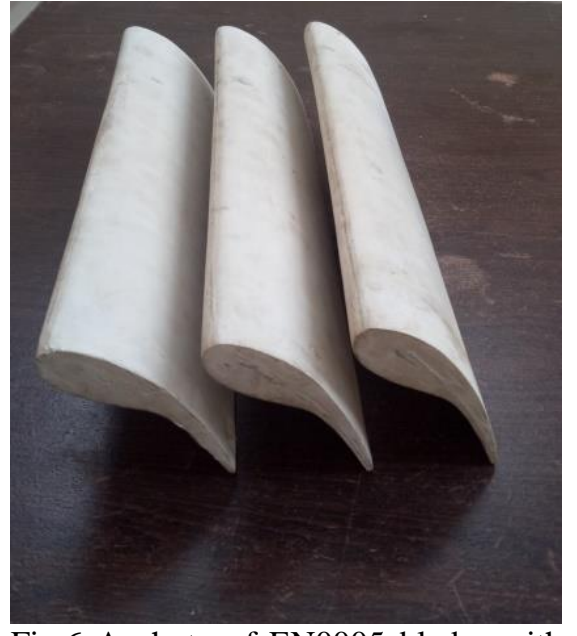

Fig.6 A photo of EN0005 blades with $0.12 \mathrm{~m}$ chord length

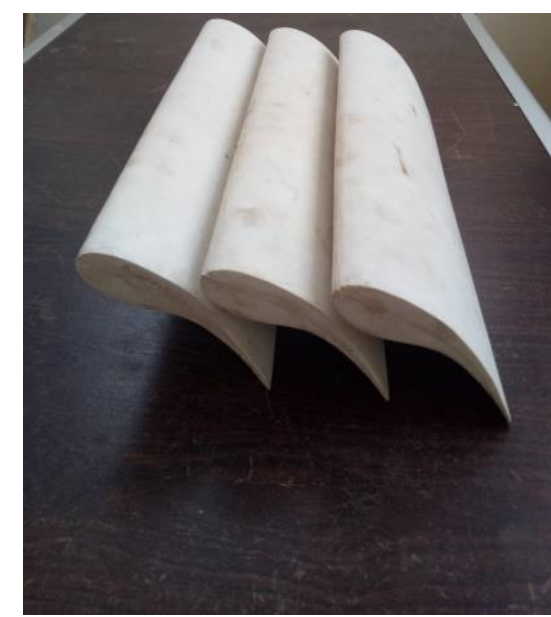

Fig.7 A photo of EN0005 blades with $0.14 \mathrm{~m}$ chord length

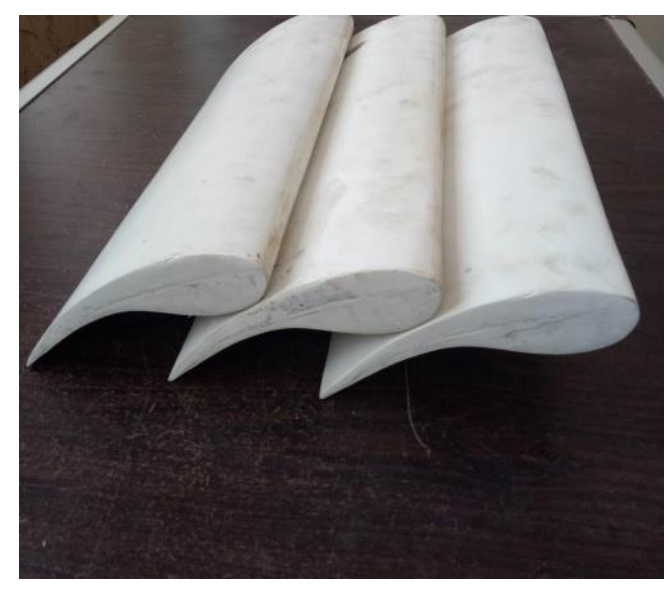

Fig.8 A photo of EN0005 blades with 0.16m chord length the experimental results in the present work are obtained using 3-bladed turbine with the new profile named EN0005 at different wind speeds and chord length as shown in Fig. 5- 8. 


\section{3-1 Effect of wind speed}

Wind speed is one of the main parameters that delineates and describes the performance of Darrieus rotor so; in the present work different wind speeds are measured. In this study, the effect of wind speed on the performance of six aspect ratio, namely $\mathrm{AR}=$ $1.3,1.25,1.143,0.952,0.833$ and 0.8 for Darrieus rotor is investigated experimentally. Fig. 9 shows the power coefficient $(\mathrm{Cp})$ as a function of blade tip speed ratio $(\lambda)$ at different wind speeds $(\mathrm{V})$. It is observed that, the power coefficient of wind turbine is increased with increasing the wind velocity at the same tip speed ratio. Also, It should be noted that, at the highest wind speed the maximum performance occurs at a tip speed ratio $(\lambda)$ around one.

\section{3-2 Effect of aspect ratio}

In order to understand the effect of aspect ratio on the performance of Darrieus wind turbine, six aspect ratios namely $\mathrm{AR}=1.3,1.25,1.143,0.952,0.833$, 0.8 are used. In this section the experimental results for chord length $0.16 \mathrm{~m}$ and different aspect ratios at the same wind speed is presented in Fig.10. The figure shows that change in the power coefficient $(\mathrm{Cp})$ with tip speed ratio $(\lambda)$ at different aspect ratio (AR) and the same wind speed. It is observed that, at the same wind speed, the maximum performance of Darrieus rotor occurs at aspect ratios 0.833 and 0.8 respectively. This may be explained as follows: a suitable turbine diameter is chosen and the vortices behind the turbine shaft decreases before getting to the blades. On the other hand, the minimum performance of Darrieus rotor occurred at aspect ratio of 1.3 , as the blades is much close to the turbine shaft and the vortices zone.

\section{3-3 Effect of chord length}

One of the most important parameters that affect the performance of Darrieus rotor is the chord length. In order to study the effect of chord length on the Darrieus performance four chord

lengths $(\mathrm{CL}=0.12,0.14,0.16$, and $0.18 \mathrm{~m})$ at $\mathrm{AR}=$ 0.952 and the same wind speed are used. Fig. 11 shows the power coefficient as a function of tip speed ratio at different chord lengths. It is noted that, as the chord length increases, the power coefficient is improved. This is because the aerodynamic force on the blades increases due to an increase in the projected area. Also, when the chord length increases the Reynolds number $(\mathrm{Re})$ increases and hence the turbine performance is improved.

\section{4- Conclusions}

In the present study an experimental investigation for the evaluation of the performance of straight bladed Darrieus rotor with new profile EN 0005 is selected as a base airfoil in this work in an attempt to improve the performance. For this, six aspect ratios and four chord lengths are experimentally tested. it can be concluded From the experimental results that:

1- The performance of Darrieus rotor increases with the wind velocity The higher the wind speed the higher the maximum average power coefficient.

2- The maximum performance of Darrieus rotor strongly depends on the aspect ratio. Increasing the aspect ratio has a negative effect on the performance, and the maximum performance occurs at aspect ratios of 0.833 and 0.8 respectively.

3- The effect of chord length on the performance is also presented. It was noted that, the coefficient of power is enhanced with the increase in the chord length and the maximum performance occurred at $\mathrm{CL}=0.18 \mathrm{~m}$ at the same aspect ratio and wind velocity. 

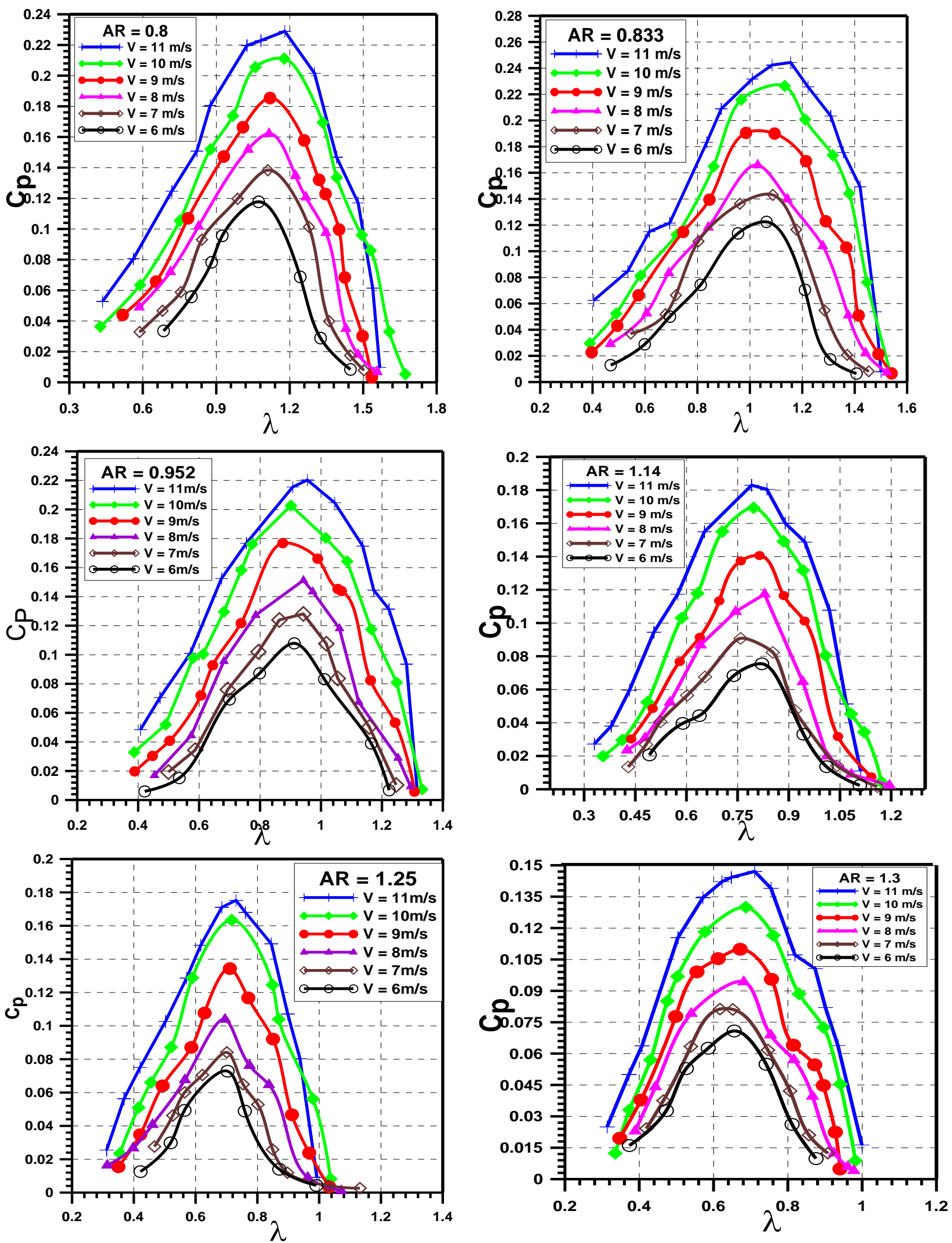

Fig. 9 Experimental variation of the power coefficient with the tip speed ratio at different wind velocities and aspect ratios 

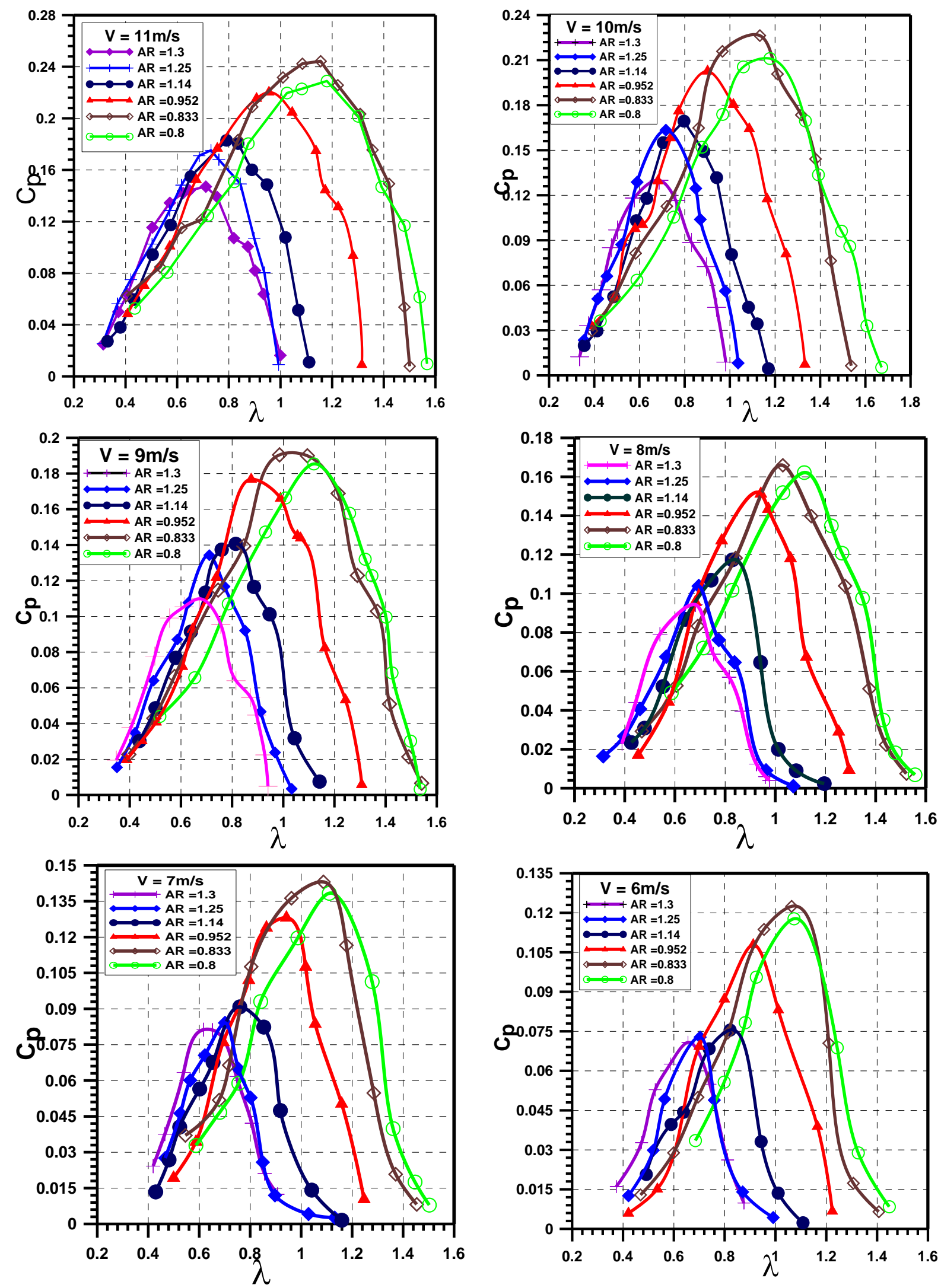

Fig. 10 Experimental variation of the power coefficient with the tip speed ratio at various aspect ratios at the same velocity 
K. A. Ibrahim, W. A. El-Askary, Tarek A. Ghonim and Ahmed M. Nebiewa" An Experimental ..."
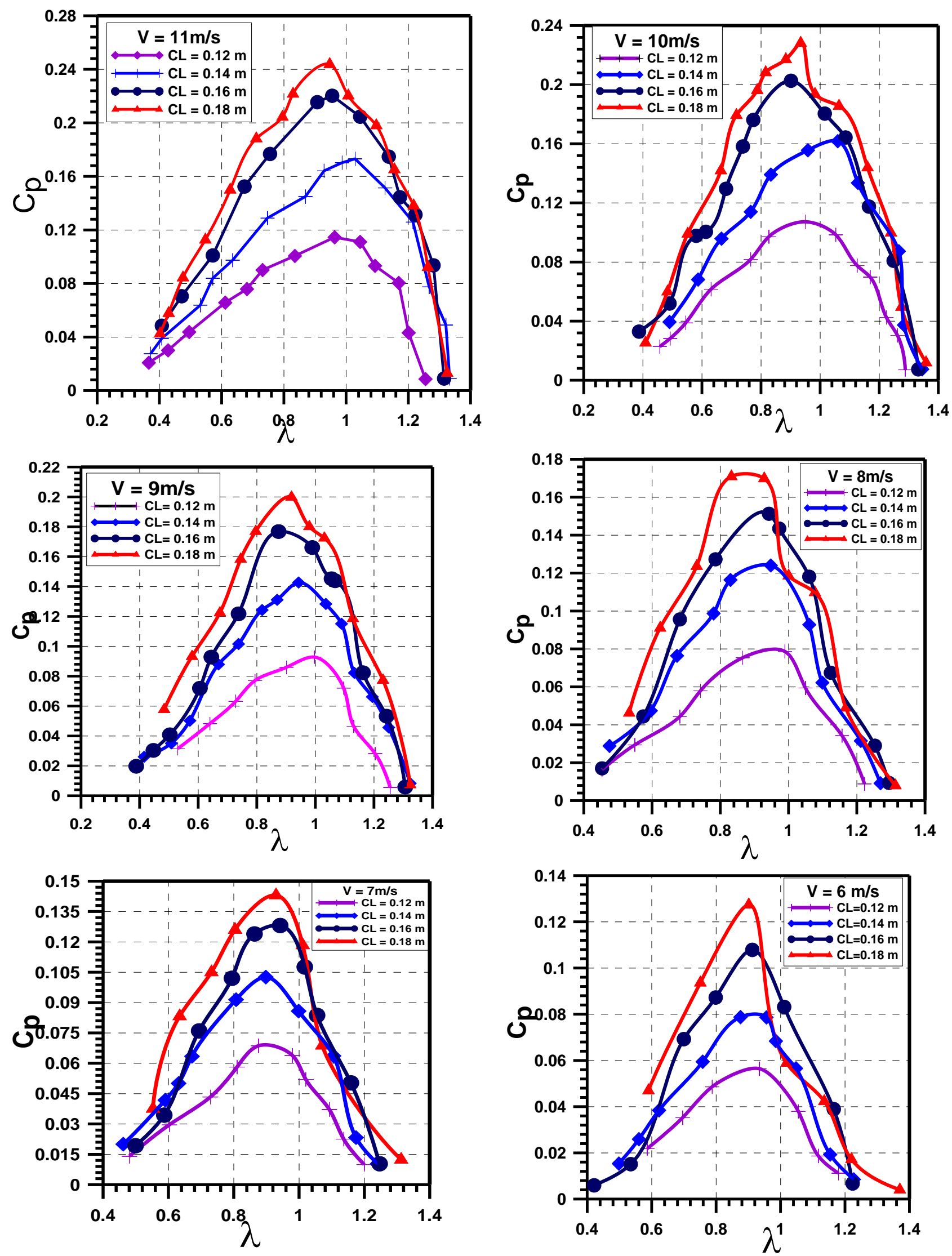

Fig. 11 The power coefficient as a function of tip speed ratio at different chord length 


\section{Nomenclature:}

A : Swept area, $\mathrm{m}^{2}$

AR : Aspect ratio, [-]

$\mathrm{CL}$ : Blade chord length, $\mathrm{m}$.

$\mathrm{C}_{\mathrm{p}}$ : Power coefficient,[-].

$\mathrm{H}$ : Blade height, $\mathrm{m}$

$\mathrm{N}$ : Rotational speed, rpm

$\mathrm{n}$ : Blade number

$\mathrm{V}$ : Wind speed, $\mathrm{m} / \mathrm{s}$.

\section{Greek Symbol:}

$\lambda$ : Tip speed ratio

$\rho$ : Density of air, $\mathrm{kg} / \mathrm{m}^{3}$

$\omega$ : Angular speed, $\mathrm{S}^{-1}$

\section{References:}

1-World wind energy association (WWEA) report. 17th world wind energy conference andexhibition2018.https://wwindea.org/blog/2019/ 02/25/wind-power-capacity-worldwide-reaches600-gw-539-gw-added-in-2018/.

2- S. Eriksson, H. Bernhoff, and M. Leijon., "Evaluation of different turbine concepts for wind power," Renew. Sustain. Energy Rev., vol. 12, no. 5, pp. 1419-1434, 2008.

3- S.H. Yoon, H.C. Lim, and D.K. Kim, "Study of several design parameters on multi-blade vertical axis wind turbine," Int. J. Precis. Eng. Manuf., vol. 14,no. 5, pp. 831-837, 2013.

4- B. Shahizare, N. Nik-Ghazali , W.T. Chong, S. Tabatabaeikia, Nima Izadyar, Alireza Esmaeilzadeh. "Novel investigation of the different Omni-direction-guide-vane angles effects on the urban vertical axis wind turbine output power via three-dimensional numerical simulation", Energy Conversion and Management, Vol. 117, pp. 206-217, 2016.

5- Jianyang Zhu, Hailin Huang and Hao Shen.” Selfstarting aerodynamics analysis of vertical axis wind turbine", Research Article, Advances in Mechanical Engineering, Vol.7, pp.1-12, 2015.

6- Md. Jahangir Alam, M.T. Iqbal. "Design and development of hybrid vertical axis turbine", CCECE '09, pp. 1178- 183, 2009.

7- T. Wakui, Y. Tanzawa, T. Hashizume, T. Nagao. "Hybrid configuration of Darrieus and Savonieus rotors for stand- alone wind turbine-generator systems", IEEJ Trans. Electr. Electron. Eng; Vol.2, pp.259-266, 2004.
8- Chirag Soni and Smit Thakkar. " Review on Aerodynamic Performance Evaluation of Straight Blade Vertical Axis Wind Turbine", International Journal for Scientific Research and Development, Vol. 2, 2014.

9- N.C. Batista, R. Melício, J.C.O.Matias, and J.P.S. Catalão." New blade profile for Darrieus wind turbine capable to self-start", Center for Innovation in Electrical and Energy Engineering, IST, Lisbon, Portugal.,2011.

10- N.C. Batista , R. Melício , J.C.O. Matias , and J.P.S. Catalão. "Self-Start Evaluation in Lift-Type Vertical Axis Wind Turbines: Methodology and Computational Tool Applied to Asymmetrical Airfoils, 2011.

11- N.C. Batista, R. Melício, J.C.O. Matias and J.P.S. Catalão." Self-Start Performance Evaluation in Darrieus-Type Vertical Axis Wind Turbine Methodology and Computational Tool Applied to Symmetrical Airfoils", RE\& PQJ, Vol.1, NO.9, 2011.

12- A.R. Sengupta , A. Biswas ,and R. Gupta. "Studies of some high solidity symmetrical and unsymmetrical blade H-Darrieus rotors with respect to starting characteristics, dynamic performances and flow physics in low wind streams", Renew. Energy, vol.93 , pp. 1-13, 2015.

13- Alexandru-Mihai CISMILIANU, Alexandru BOROS, Ionut-Cosmin ONCESCU, and Florin FRUNZULICA. "New Urban Vertical Axis Wind Turbine Design", 36th "Caius Iacob" Conference on Fluid Mechanics and its Technical Applications, Vol.7, pp.67-76, 2015.

14- Mojtaba Tahani, Narek Babayan, Seyedmajid Mehrnia, Mehran Shadmehri, "A novel heuristic method for optimization of straight blade vertical axis wind turbine", Energy Conversion and Management, Vol.127, PP.461-476, 2010.

15- M. El-Samanoudy, A.A.E. Ghorab, and Sh.Z. Youssef. "Eff ect of some design parameters on the performance of a Giromill vertical axis wind turbine", Ain Shams Engineering Journal, Vol.1, PP.85-95, 2010.

16- M.H. Nasef, W.A. El-Askary, A.A. AbdELhamid, H.E. Gad. "Evaluation of Savonius rotor performance: Static and dynamic studies", J. Wind Eng. Ind. Aerodyn, vol. 123, P.P. 1-11, 2013. 